\title{
The Compulsive Internet Use Scale (CIUS) Adapted to Assess Excessive Multiplayer Gaming
}

Antonia Barke*, Nele Nyenhuis, Till Voigts, Hans Gehrke and Birgit Kröner-Herwig

Department of Clinical Psychology and Psychotherapy, Georg-August-University Göttingen, Goßlerstr, 14, 37073 Göttingen, Germany

\begin{abstract}
Introduction: There is a growing need for an instrument generating reliable scores and permitting valid interpretations regarding the excessive use of internet and video games. So far there is no specific questionnaire to address the excessive use of online games. The Compulsive Internet Use Scale (CIUS) measures the construct of compulsive internet use. The English version is brief and possesses good psychometric properties. We translated it into German and adapted it to online gaming, in particular playing World of Warcraft $($ WoW).
\end{abstract}

Method: A sample of 935 WoW players (mean age $23.3 \pm 6.4$ years, $78.1 \%$ male) completed an online version of the adapted CIUS-WoW and provided information on the time they spend playing WoW in a typical week. Item and reliability analyses were computed. In order to investigate the component structure the sample was randomly divided into two subsamples and a principal component analysis conducted for one subsample and a confirmatory factor analysis for the other subsample.

Results: The CIUS-WoW scores possessed good internal consistency (Cronbach's $\alpha=.86$ ). A two-component structure with the components Loss of Control and Commitment and a single component structure showed an acceptable fit. The CIUS-WoW score correlated with the time spent playing WoW in a typical week $(r=.44)$.

Discussion: The adapted CIUS-WoW produced scores with good internal consistency close to that of the original version. The correlation with time spent playing in a typical week is a first indication that it allows valid interpretations.

Keywords: MMORPG; World of warcraft; Validation; German; questionnaire

\section{Introduction}

The use of internet games has soared in the last few years with the market for online games growing from $\$ 770$ million in 1988 to $\$ 2.06$ billion in 2001 [1], and is expected to reach $\$ 29$ billion by 2016 [2]. Market leaders are the so called 'Massively Multi-Player Online Role Playing Games' (MMORPGs). Two central characteristics of MMORPGs are that a large numbers of players play together in a single game and that this game's virtual world stays in existence when the individual user disconnects [3]. In addition, MMORPGs have no natural end point of playing content, as for example one final battle. Rather, the users can continue to play endlessly. The most widely played MMORPG is World of Warcraft $₫$ (WoW) from Blizzard Entertainment $\odot$, which 2010 was played by more than 12 million users worldwide [4]

In parallel to the growth in revenues, there has been an increase in the number of people who seek counselling for their online gaming and who report that they experience negative consequences of the gaming for their well-being [5]. Compared to players of other computer games, MMORPG players spend more time playing [6,7], report worse health and sleep quality [7], more often develop overuse and report more depressive symptoms and lower self-esteem [8], as well as more withdrawal and anxiety [9]. They also report more interference with offline social life and academic work [7]. High frequency game play is associated with increased anxiety and depression [10]. A third of German 15-year-old male players spend over 4.5 hours playing WoW each day, and about a fifth were classified as "dependent" on gaming, or prone to such a dependency in a large study investigating a representative sample $(\mathrm{n}=44.610)$ by Rehbein et al. [11].

Research into excessive use of online gaming is hampered by the absence of agreed terminology and a lack of a consensus about diagnostic criteria. Internet gaming disorder will be included in section
III (disorders that warrant further research) of the DSM-5 [12]. Several instruments for measuring excessive internet use in general have been developed (Internet Addiction Test (IAT) [13], Compulsive Internet Use Scale (CIUS) [14], and Generalized Problematic Internet Use Scale 2 [15]). However, an instrument assessing excessive use of MMORPGs is at present lacking. The purpose of this study was to adapt the Compulsive Internet Use Scale (CIUS) developed by Meerkerk and colleagues [14] to measure excessive use of MMORPGs. The original CIUS measures compulsive internet use and consists of 14 items, which are rated on a 5-point scale from 0 to 4 (never, seldom, sometimes, often, very often). A sum score is calculated, which ranges from 0 to 56 . In order to arrive at the items of the CIUS, the original authors reviewed the DSM-IV criteria for substance dependence and pathological gambling [16] as well as Griffiths' criteria for behavioral addictions [17]. The items of the CIUS were then formulated to capture those five aspects of behavioral addictions that in a small qualitative pilot study among internet users appeared to be most important, namely loss of control (items 1,2, 5 and 9), preoccupation (items 4, 6 and 7), withdrawal symptoms (item 14), coping or mood modification (items 12 and 13) and conflict (items $3,8,10$ and 11). The original CIUS is brief and has good psychometric properties: the internal consistency of its item scores is

*Corresponding author: Dr. Antonia Barke, Department of Clinical Psychology and Psychotherapy, Georg-August-University Göttingen, Goßlerstr. 14, 37073 Göttingen, Germany, Tel: +49-551-395502; Fax: +49-551-393544;E-mail: abarke@uni-goettingen.de

Received September 23, 2013; Accepted October 31, 2013; Published November 10, 2013

Citation: Barke A, Nyenhuis N, Voigts T, Gehrke H, Kröner-Herwig B (2013) The Compulsive Internet Use Scale (CIUS) Adapted to Assess Excessive Multiplayer Gaming. J Addict Res Ther 4: 164. doi: 10.4172/2155-6105.1000164

Copyright: ( 2013 Barke A, et al. This is an open-access article distributed under the terms of the Creative Commons Attribution License, which permits unrestricted use, distribution, and reproduction in any medium, provided the original author and source are credited. 
high (Cronbach's $\alpha=.89$ ) and the sum score correlates with the time spent on the internet from $r=.33$ to $r=.42$. The questionnaires' authors calculated a confirmatory factor analysis and reported a one-factor structure for the CIUS. We translated the scale into German, adapted it to WoW and validated it with an online sample of WoW players. The CIUS was chosen for adaptation rather than the IAT, which had been validated more extensively [18-22] because the CIUS was the shortest instrument (14 rather than 20 items). In general, an instrument's length was related negatively to the return rates in clinical follow-ups [23]. In addition, a brief instrument seemed particularly suited for a population that is very reserved regarding research, which they often perceive as casting a pejorative light on themselves or their chosen pastime.

\section{Method}

\section{Translation and adaptation of the CIUS}

The CIUS was translated from English into German by the first author $(\mathrm{AB})$, a bilingual native speaker of German and English, and translated back again by a bilingual speaker. Resulting differences between the forward and the back translation were small. They were resolved through a discussion among the translators and all of the study's authors. The translated version was then adapted to capture playing the MMORPG WoW. For this purpose, the term internet was replaced with World of Warcraft and the word use with play in all items of the questionnaire. Subsequently, the resulting questionnaire was pretested on a small number of students using online games to ascertain whether the wording seemed appropriate and readily understandable; this being so, no changes to the instrument resulted from this step. No further modifications were made.

\section{Procedure}

The online survey consisting of the modified CIUS-WoW, questions about the sex, age, and time spent playing WoW in a typical week was placed on the servers of Survey Monkey® (www.surveymonkey.com). The survey was advertised in WoW specific groups of the German social networking site StudiVz, which has approximately 16 million users (StudiVz Ltd. 2012). In addition, the internet was searched for WoW guilds and an invitation to participate in the survey was placed on their forums. The text of the invitation was always the same and included the link to the online survey. If the participants followed the link, they saw an instruction, which informed them that their answers would be anonymous. The participants could then choose to take part in the survey by clicking a consent button or to leave the site. No incentives were given for participation.

\section{Sample}

A total of 1379 persons visited the initial link, 376 of these were excluded because they did not complete the questionnaire. A further 68 persons had to be excluded from the analysis because they did not answer the questions seriously (e.g. stating that they were 110 years old). Data for 935 participants were included in the analysis. Of the 935 participants, 729 (78.1\%) were male. The ages of the participants ranged from 12-75; on average, the participants were 23.3 ( \pm SD 6.4) years old and had played WoW for $3.7 \pm 1.4$ years.

\section{Statistical analysis}

We calculated internal consistency (Cronbach's $\alpha$ ), item difficulties, and corrected item-total correlations of the translated and adapted version of the CIUS-WoW. In order to investigate the component structure, the sample was divided randomly into two subsamples and a principal components analysis (PCA) was computed for the first sub- sample and a confirmatory factor analysis (CFA) was conducted for the second subsample. For the random allocation, each participant was allocated a random number ( 0 or 1$)$ by a computerized random number generator. Participants with 0 were assigned to the first subsample, participants with 1 to the second. For the PCA, the suitability of the data for the analysis was tested with the Kaiser-Meyer-Olkin measure of sampling adequacy and Bartlett's test of sphericity. After the extraction of the components by means of the PCA, the number of components to be retained was determined through Horn's parallel analysis [24]. The resulting components were rotated according to varimax. The CFA was conducted to test the fit of the component structure in an independent sample. As measures for the goodness of fit, the $\chi^{2}$ test, the root mean square error of approximation, the standardized root mean squared residual, the comparative fit and the expected cross-validation index are reported. Pearson correlations of the CIUS-WoW score and the time spent playing WoW per week were calculated as first indicators of the validity of the CIUS-WoW. In order to investigate whether there were any sex differences in the number of hours spent playing WoW per week or in the CIUS-WoW scores, we used independent $t$ tests.

\section{Results}

The CIUS-WoW item scores achieved an internal consistency of Cronbach's $\alpha=.86$. The mean item difficulty was $p_{\mathrm{i}}=.27$, with difficulties ranging from $p_{\mathrm{i}}=.09$ (item 14) to $p_{\mathrm{i}}=.57$ (item 7). The mean CIUS-WoW score across all participants was $15.5 \pm 8.7$. The corrected item-total correlations ranged from $r_{\text {itc }}=.29$ (item 7) to $r_{\text {itc }}=.65$ (item 1 ), with a mean item-total correlation of $r_{\text {itc }}=.52$ (Table 1).

The two subsamples resulting from the random division of the sample for the purpose of the PCA and the CFA did not differ regarding age, sex, years that the game had been played, gaming hours per week or CIUS scores (Table 2).

Subsample 1 was used to compute a PCA. Bartlett's test $\left(\chi^{2}=\right.$ 2176.28, $d f=91, p<.0001)$ and the KMO criterion $(\mathrm{KMO}=.883)$ showed excellent suitability of the data for such an analysis. The PCA extracted two components that were retained by Horn's parallel analysis. After varimax rotation the items 1, 4-7, 10 and 14 loaded on one component that could be characterized as Loss of Control and the items $2,3,8,9$, and $11-13$ on a second component that could be termed Commitment (for the loadings of the components see Table 3). Together, the extracted components explained $47.02 \%$ of the variance. The correlation between the components was $r=.62, p<.001$.

The CFA calculated on the basis of subsample 2 confirmed the extraction of two components (Figure 1a for the path diagram) and showed a reasonable fit of the model (Table 4). Because of the high correlation of the components and the high cross-loadings for some items (most notably items 1 and 11), we also tested whether a onefactor model might fit the data (Figure $1 \mathrm{~b}$ for the path diagram) and found a comparable fit to that of the two-factor model (See Table 4 for a comparison of the fit indices). We also tested the one-factor model proposed by the original authors [14], who permitted covariation between the items 1 and 2, 6 and 7, 8 and 9, 10 and 11 as well as 12 and 13. This model showed a better fit than either the one-factor model without these covariations or the two-factor model. (See Table 4 for a comparison of the fit indices.)

The CIUS-WoW score correlated with the reported number of hours $(\mathrm{M}=21.7 \pm 16.3)$ spent playing WoW per week $(r=.44, p<$ $.001)$. For details of playing time per week see Figure 2 and for CIUSWoW scores plotted against weekly playing time see Figure 3. 
Citation: Barke A, Nyenhuis N, Voigts T, Gehrke H, Kröner-Herwig B (2013) The Compulsive Internet Use Scale (CIUS) Adapted to Assess Excessive Multiplayer Gaming. J Addict Res Ther 4: 164. doi: 10.4172/2155-6105.1000164

Page 3 of 6

Table 1: Means, standard deviations, item difficulties, corrected item-total correlations, internal consistencies without each item $(n=935)$.

\begin{tabular}{|c|c|c|c|c|c|}
\hline & Mean & SD & Item difficulty & $\begin{array}{l}\text { Item-Total Correlation } \\
\text { (corrected) }\end{array}$ & $\begin{array}{l}\text { Alpha without } \\
\text { item }\end{array}$ \\
\hline $\begin{array}{l}\text { 1. Wie oft fällt es dir schwer dein WoW-Spielen zu beenden, wenn du online bist? } \\
\text { [How often do you find it difficult to stop playing WoW when you are online?] }\end{array}$ & 1.07 & 0.94 & .26 & .65 & .85 \\
\hline $\begin{array}{l}\text { 2. Wie oft spielst du WoW weiter, obwohl du die Absicht hast aufzuhören? } \\
\text { [How often do you continue to play WoW despite your intention to stop?] }\end{array}$ & 1.02 & 1.02 & .25 & .50 & .85 \\
\hline $\begin{array}{l}\text { 3. Wie oft sagen andere (z.B. Partner, Kinder, Eltern), dass du WoW weniger spielen } \\
\text { sollst? } \\
\text { [How often do others (e.g. partner, children, parents) say you should play less WoW?] }\end{array}$ & 1.28 & 1.24 & .31 & .52 & .85 \\
\hline $\begin{array}{l}\text { 4. Wie oft spielst du lieber WoW als Zeit mit anderen (z.B. Partner, Kinder, Eltern) zu } \\
\text { verbringen? } \\
\text { [How often do you prefer to play WoW instead of spending time with others (e.g. } \\
\text { partner, children, parents)?] }\end{array}$ & 0.92 & 1.04 & .22 & .53 & .85 \\
\hline $\begin{array}{l}\text { 5. Wie oft schläfst du wegen WoW zu wenig? } \\
\text { [How often are you short of sleep because of playing WoW?] }\end{array}$ & 0.90 & 1.07 & .22 & .51 & .85 \\
\hline $\begin{array}{l}\text { 6. Wie oft denkst du an WoW, auch wenn du nicht online bist? } \\
\text { [How often do you think about WoW when you are not online?] }\end{array}$ & 1.71 & 0.95 & .42 & .49 & .85 \\
\hline $\begin{array}{l}\text { 7. Wie oft freust du dich auf deine nächste WoW- Sitzung? } \\
\text { [How often do you look forward to your next WoW session?] }\end{array}$ & 2.30 & 0.91 & .57 & .29 & .86 \\
\hline $\begin{array}{l}\text { 8. Wie oft denkst du, dass du WoW seltener spielen solltest? } \\
\text { [How often do you think you should play WoW less often?] }\end{array}$ & 1.41 & 1.10 & .35 & .44 & .86 \\
\hline $\begin{array}{l}\text { 9. Wie oft hast du erfolglos versucht, weniger Zeit mit WoW zuzubringen? } \\
\text { [How often have you unsuccessfully tried to spend less time playing WoW?] }\end{array}$ & 0.47 & 0.86 & .11 & .51 & .85 \\
\hline $\begin{array}{l}\text { 10. Wie oft beeilst du dich mit deiner Arbeit / Hausaufgaben, um WoW spielen zu } \\
\text { können? } \\
\text { [How often do you rush through your (home) work in order to play WoW?] }\end{array}$ & 0.92 & 1.11 & .22 & .60 & .85 \\
\hline $\begin{array}{l}\text { 11. Wie oft vernachlässigst du deine alltäglichen Verpflichtungen (Arbeit, Schule oder } \\
\text { Familienleben), weil du lieber WoW spielst? } \\
\text { [How often do you neglect your daily obligations (work, school, or family life) because } \\
\text { you prefer to play WoW?] }\end{array}$ & 0.82 & 1.05 & .20 & .63 & .85 \\
\hline $\begin{array}{l}\text { 12. Wie oft spielst du WoW, wenn du dich schlecht fühlst? } \\
\text { [How often do you play WoW when you are feeling down?] }\end{array}$ & 1.31 & 1.13 & .32 & .47 & .86 \\
\hline $\begin{array}{l}\text { 13. Wie oft benutzt du WoW, um deine Sorgen zu vergessen oder mit negativen } \\
\text { Gefühlen fertig zu werden? } \\
\text { [How often do you play WoW to escape from your sorrows or get relief from negative } \\
\text { feelings?] }\end{array}$ & 0.98 & 1.19 & .24 & .47 & .86 \\
\hline $\begin{array}{l}\text { 14. Wie oft fühlst du dich rastlos, frustriert oder gereizt, wenn du nicht WoW spielen } \\
\text { kannst? } \\
\text { [How often do you feel restless, frustrated, or irritated when you cannot play WoW?] }\end{array}$ & 0.36 & 0.75 & .09 & .61 & .85 \\
\hline
\end{tabular}

Note: The English language items are provided for illustration purposes.

Table 2: Characteristics of the two subsamples resulting from the random division of the total sample for the purpose of the exploratory and confirmatory factor analyses

\begin{tabular}{|c|c|c|c|c|c|c|}
\hline & \multicolumn{2}{|c|}{ Subsample $1(n=489)$} & \multicolumn{2}{|c|}{ Subsample $2(n=446)$} & \multirow{2}{*}{$(d f=933)$} & \multirow[t]{2}{*}{$\mathrm{p}$} \\
\hline & Mean & SD & Mean & SD & & \\
\hline Age (years) & 23.4 & 6.7 & 23.3 & 6.0 & 0.321 & .748 \\
\hline Years of gaming & 3.6 & 1.4 & 3.7 & 1.4 & -0.209 & .834 \\
\hline Gaming hours per week & 22.0 & 15.5 & 21.4 & 17.3 & 0.532 & .594 \\
\hline CIUS score & 15.7 & 8.7 & 15.2 & 8.6 & 0.984 & .325 \\
\hline & Men & Women & Men & Women & $\mathrm{X}^{2}(d f=1)$ & \\
\hline Sex & 382 & 107 & 347 & 99 & 0.014 & .907 \\
\hline
\end{tabular}

Males did not spend more hours playing WoW per week $(22.3 \pm$ 16.4) than females $(19.8 \pm 16.2), t(933)=1.93, p>.05, d=0.15$, and did not achieve higher CIUS-WoW scores $(15.6 \pm 8.8)$ than females $(14.9 \pm 8.2), t(933)=1.10, p>.10, d=0.09$. Regarding the individual components, males showed a tendency to score higher on Loss of Control $(7.4 \pm 5.1)$ than females $(6.8 \pm 4.6), t(933)=1.681, p=.093, d=$ 0.14 , whereas no difference was found for the component Commitment (males: $8.2 \pm 4.6$, females: $8.1 \pm 4.4), t(933)=0.28, p>.10, d=0.02$. Age correlated negatively with the time spent playing per week $(r=-.15, p<$ $.001)$, with the CIUS score $(r=-.12, \mathrm{p}<.001)$ and with the components Loss of Control $(r=-.13, p<.001)$ and Commitment $(r=-.09, p<.01)$.

\section{Discussion}

The aim of this study was to adapt the CIUS to the MMORPG WoW and validate the German adapted version in a sample of WoW players. The CIUS-WoW scores were shown to possess good internal consistency $(\alpha=.86)$, almost reaching the value reported for the original CIUS ( $\alpha=.89$ ) [14]. The internal consistency would not have profited from dropping any item. The item total correlations were in the range of medium to high, with a mean item total correlation of $\mathrm{r}_{\mathrm{itc}}=.52$ demonstrating a good discriminatory power of the items.

The item with the highest endorsement (i.e. the lowest difficulty) was item 7 "How often do you look forward to your next WoW session?" whereas the most difficult, that is to say least endorsed, item 
Citation: Barke A, Nyenhuis N, Voigts T, Gehrke H, Kröner-Herwig B (2013) The Compulsive Internet Use Scale (CIUS) Adapted to Assess Excessive Multiplayer Gaming. J Addict Res Ther 4: 164. doi: 10.4172/2155-6105.1000164

Page 4 of 6

Table 3: Results of the principal component analysis (Subsample 1: $n=489$ ): Loadings of the components

\begin{tabular}{|l|l|l|}
\hline & Component I Loss of Control & Component II Commitment \\
\hline Item 8 & .77 & -.03 \\
\hline Item 9 & .74 & .13 \\
\hline Item 3 & .60 & .31 \\
\hline Item 2 & .53 & .35 \\
\hline Item 11 & .53 & .49 \\
\hline Item 13 & .48 & .20 \\
\hline Item 12 & .47 & .34 \\
\hline Item 7 & -.21 & .70 \\
\hline Item 6 & .08 &. $\mathbf{6 8}$ \\
\hline Item 10 & .27 &. $\mathbf{6 7}$ \\
\hline Item 4 & .24 &. $\mathbf{6 1}$ \\
\hline Item 1 & .46 &. $\mathbf{6 1}$ \\
\hline Item 14 & .35 &. $\mathbf{5 9}$ \\
\hline Item 5 & .34 &. $\mathbf{5 1}$ \\
\hline Eigenvalue & 3.41 & 3.17 \\
\hline Explained Variance & $24.38 \%$ & $22.64 \%$ \\
\hline Standardized Alpha & .78 & .80 \\
\hline
\end{tabular}

was item 14, "How often do you feel restless, frustrated, or irritated when you cannot play WoW?" Considering that a majority of people use WoW recreationally and without adverse consequences, it seems plausible that the item with the highest endorsement should focus on the enjoyment and anticipation, and that the lowest endorsement should be generated by an item related to experiencing symptoms akin to withdrawal, which one would expect to be comparatively low in a general sample of players. On average the items were of medium difficulty $\left(p_{\mathrm{i}}=.27\right)$ for this population.

The PCA revealed two components, which together explained 47\% of the variance. The first component could be characterized as Loss of Control, with the highest loading items being "How often have you unsuccessfully tried to spend less time playing WoW?" and "How often do you think you should play WoW less often?" The second component could be characterized as Commitment with the highest loading items being "How often do you look forward to your next WoW session?" and "How often do you think about WoW, even when not online?", which focus on the enjoyment of, and commitment to, the game. The two components were correlated $(r=.61)$ and the after the varimax
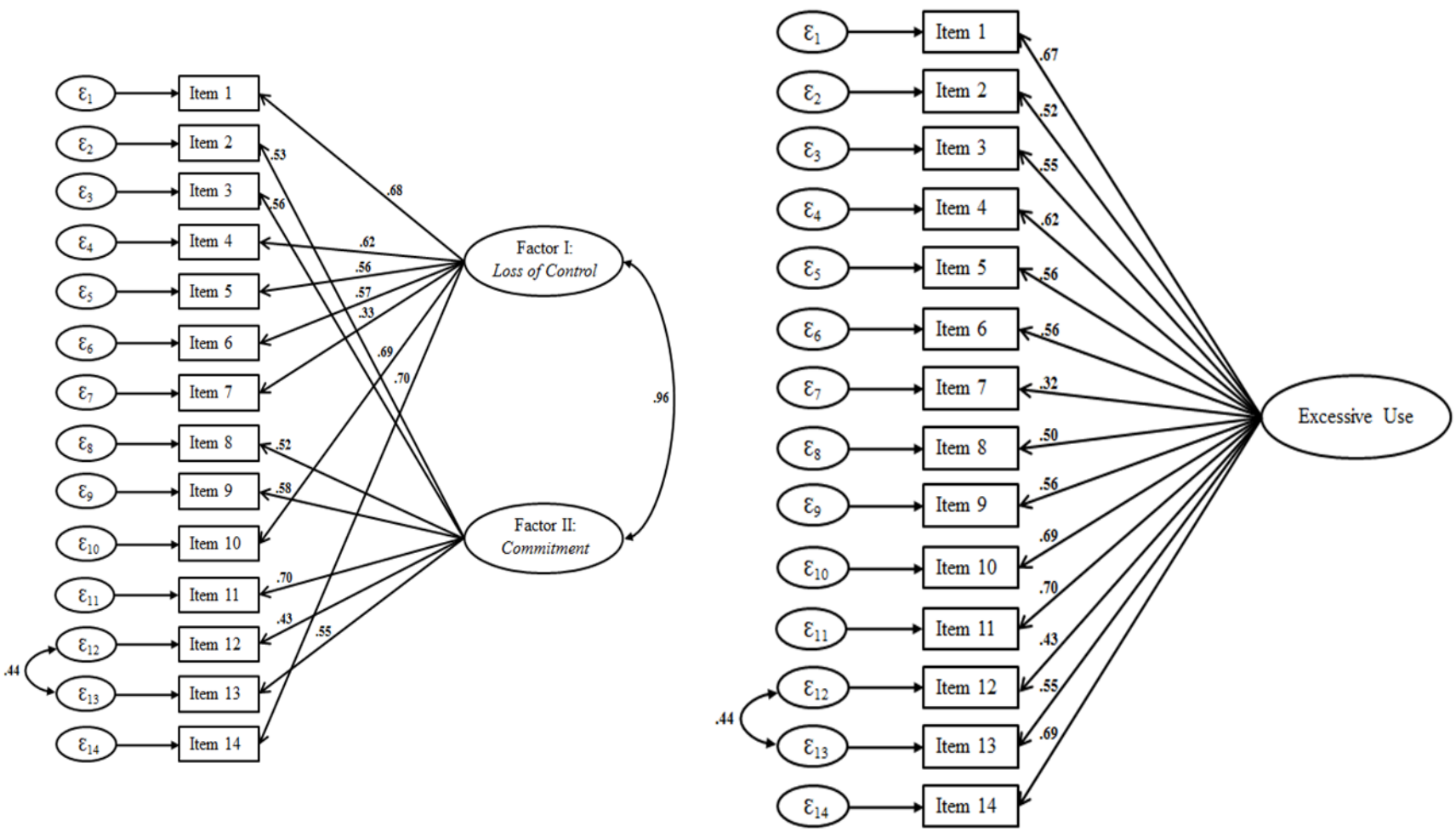

Figures 1a and b: Path diagrams for the confirmatory factor analysis showing the two-factor structure (1a) and the one-factor structure (1b) with the standardized path coefficients for subsample $2(n=446)$. We allowed a co-variation of items 12 and 13 due to their very similar content (using the online gaming to cope with negative feelings)

Table 4: Results of the confirmatory factor analysis $(n=446)$

\begin{tabular}{|l|l|l|l|l|l|l|l|}
\hline Model & $\mathrm{X}^{2}$ & $\mathrm{df}$ & $\chi^{2} / \mathrm{df}$ & RMSEA [CI] & SRMR & CFI & ECVI [CI] \\
\hline 2-factor model & 293.33 & 75 & 3.91 & $.081[.071-.091]$ & .0555 & .858 \\
\hline 1-factor model & 296.45 & 76 & 3.90 & $.081[.071-.091]$ & .0559 & .887 \\
\hline 1-factor model & 215.20 & 72 & 2.99 & $.067[.057-.077]$ & .0477 & $.984]$ \\
\hline
\end{tabular}

Notes: ane-factor model as suggested by the original authors with covariations between items 1 and 2, 6 and 7, 8 and 9, 10 and 11,12 and 13 .

RMSEA: Root Mean Square Error of Approximation; SRMR: Standardized Root Mean Squared Residual; CFI: Comparative Fit Index; ECVI: Expected Cross Validation Index 


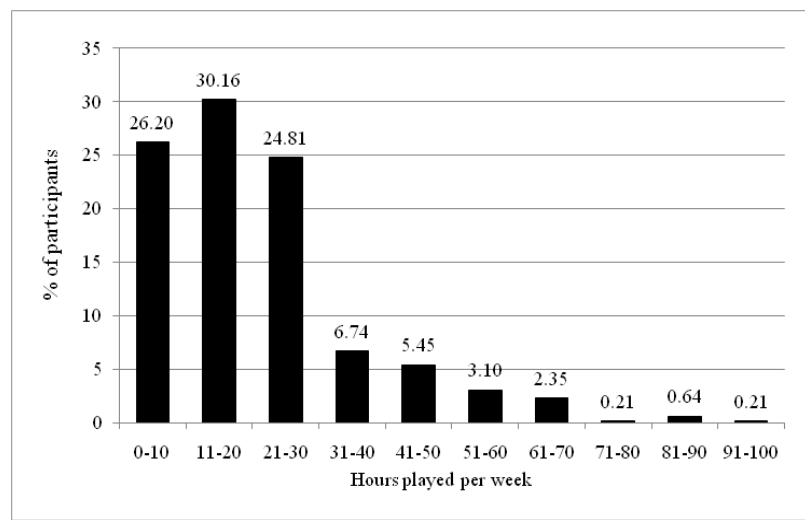

Figure 2: Weekly playing hours reported by the participants

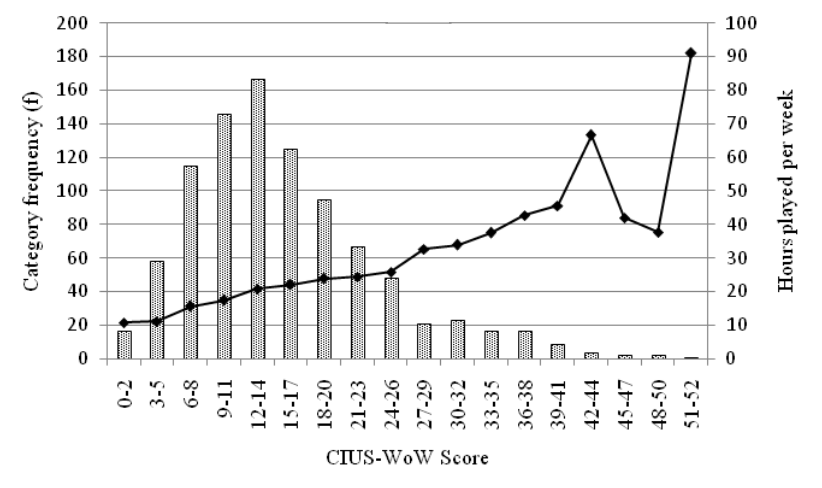

Figure 3: Weekly playing hours averaged for CIUS-WoW score ranges with columns showing the number of participants who achieved scores in the range indicated and the line depicting the average number of hours played by these participants.

Note that the number of participants who scored higher than 42 on the questionnaire is very low, so there are very few cases in the respective categories leading to a stronger fluctuation in the time scores for statistical reasons.

rotation some items still showed high crossloadings, the highest being found for item 11 ("How often do you neglect your daily obligations (work, school, or family life) because you prefer to play WoW?") and item 1 ("How often do you find it difficult to stop playing WoW when you are online?").

The CFA with a second, independent sample also found some evidence for the proposed two-component solution with an RMSEA of .08 and an SRMR of .056. According to Schreiber and coworkers an RMSEA of .08 and an SRMR $\leq .08$ indicate an acceptable fit [25]. The CFI of .89 and the $\chi^{2}$ value by contrast are less satisfactory. Therefore, despite the two component structure suggested by the PCA, the correlation of the components and the cross loadings led us to test whether a one-factor model would fit the data also. We found only a very marginally decreased fit for such a model compared to the twofactor model. With a comparable fit, however, the one-factor model appears preferable on the basis of its greater parsimony. Theoretically, the single factor model agrees with the original intention of creating a scale which assesses excessive use of the online game and also with the original authors' findings. They had also opted for a single-factor model, albeit a less parsimonious one, since they permitted the covariations of several items, i.e. between items 1 and 2, 6 and 7, 8 and 9, 10 and 11,
12 and 13 [14], whereas we originally only allowed items 12 and 13 to covary. Following their analysis and allowing for such covariations on the basis of the items' related content and phrasing, the model fit increased markedly in our sample.

Comparing the CIUS-WoW scores to an external criterion, the number of hours played per week, we found a medium correlation $(r=$ .44). The correlation is not affected if participants who reported playing more than 80 hours per week are excluded as outliers (without these participants: $r=.43$ ). This is close to the correlations of the original questionnaire. Meerkerk and colleagues reported a correlation with online time of $r=.33$ (study 1) and $r=.42$ (study 2). It is also in line with correlations published for other general internet questionnaires and online time. For the IAT, the German validation study found a correlation of $r=.44$ [22]; Widyanto and McMurran found correlations of $r=.30$ [18] and $r=.20$ [19], and Khazaal et al. of $r=.53$ [21].

We also found significant, but small, negative correlations for age with hours played per week, CIUS-WoW scores, and the CIUSWoW components Loss of Control and Commitment, which point to a decrease in gaming time and CIUS-WoW scores as the participants get older. However, the correlation's significance is partly due to the large sample size, and the variance explained by the correlations is very low ( $2.2 \%$ for the time spent playing per week).

In our sample, $78.1 \%$ were male. This does not seem to be a sampling bias, but a fair representation of the sex distribution of online gaming behavior, with several studies reporting that over $80 \%$ of the studied gamer populations were male [6,26-29]. Regarding sex differences in the gaming behaviour of the participants, we did not find any differences between men and women in the overall CIUS-WoW scores or time spent online. However, we observed a tendency for male WoW players to report more loss of control over their gaming. The slight male preponderance with respect to the component Loss of Control fits well with results of Desai and colleagues [30]. They reported that among high school students twice as many boys (5.9\%) than girls (3.0\%) endorsed three indicators of problematic gaming, (1) family members expressing concern about gaming, (2) trying to cut back, and (3) experiencing an irresistible urge to play. These items show a close similarity to the component Loss of Control (items 3 and 9).

The participants reported an average gaming time of almost 21.7 hours per week. This agrees well with average playing times reported by other authors for multiplayer online games [26,31]. In our sample, there is a substantial subgroup of persons (18.7\%), who played more than 30 hours per week.

Clinically, it would be useful to identify a cut-off point for online gaming addiction. The design of this study does not permit a decision on this question. However, we would tentatively suggest investigating more closely persons who score 29 points $(=$ Mean $+1.5 \mathrm{SD})$ and above. In our sample, this was true of 84 participants (8.9\%), whose average playing time amounted to 40.9 hours (for comparison purposes, in Germany a typical full-time job requires 40 hours per week). In order to achieve a score of 29 points, the person had to experience every symptom at least sometimes or often. However, whether this cut-off point is appropriate can only be determined by validation studies that compare the questionnaire data with independent clinical diagnoses.

This study is not without limitations. Of the people who followed the link, 33.2\% failed to provide data for the analyses, either because they did not complete the questionnaire or did not answer seriously. Although this percentage of dropouts was within the range of $17.2 \%$ [8] to $47.4 \%$ [32] commonly reported for online studies of online-gaming, 
Citation: Barke A, Nyenhuis N, Voigts T, Gehrke H, Kröner-Herwig B (2013) The Compulsive Internet Use Scale (CIUS) Adapted to Assess Excessive Multiplayer Gaming. J Addict Res Ther 4: 164. doi: 10.4172/2155-6105.1000164

the possibility that this influenced the results cannot be excluded. Furthermore, since no incentive was provided for participation in the study, it is likely that it was mainly people who felt strongly about the subject matter who followed the link to the questionnaire. In our view, this limitation can be tolerated considering that those participants would also be the target population of this questionnaire.

In summary, the adapted German version of the CIUS, the CIUSWoW, can be used for measuring the excessive use of WoW, and may be adapted for use with other MMORPGs in German samples.

\section{References}

1. Choi D, Kim J (2004) Why people continue to play online games: in search of critical design factors to increase customer loyalty to online contents. Cyberpsychol Behav 7: 11-24

2. Brightman J (2011) Online games market to nearly double to $\$ 29$ billion by 2016.

3. Seifert R, Jöckel S (2008) Die Welt der Kriegskunst. Nutzungsmotivation und Spielerleben im Massively Multiplayer Roleplay Game ,World of Warcraft" In Quandt T, Wimmer J, Wolling J (Eds.) Die Welt der Kriegskunst: Die Computerspieler VS Verlag für Sozialwissenschaften, Wiesbaden, pp. 297311

4. Blizzard (2010) Anzahl der Abonnenten von World of Warcraft $\circledast$ steigt weltweit auf 12 Millionen.

5. Wölfling K, Müller KW (2008) Phänomenologie, Forschung und erste therapeutische Implikationen zum Störungsbild Computerspielsucht. Psychotherapeutenjournal 2: 128-133.

6. Ng BD, Wiemer-Hastings $P$ (2005) Addiction to the internet and online gaming. Cyberpsychol Behav 8: 110-113.

7. Smyth JM (2007) Beyond self-selection in video game play: an experimental examination of the consequences of massively multiplayer online role-playing game play. Cyberpsychol Behav 10: 717-721.

8. Stetina BU, Kothgassner OD, Lehenbauer M, Kryspin-Exner I (2011) Beyond the fascination of online-games: Probing addictive behavior and depression in the world of online-gaming. Computers in Human Behavior 27: 473-79.

9. Holtz P, Appel M (2011) Internet use and video gaming predict problem behavior in early adolescence. J Adolesc 34: 49-58.

10. Mentzoni RA, Brunborg GS, Molde H, Myrseth H, Skouverøe KJ, et al. (2011) Problematic video game use: estimated prevalence and associations with mental and physical health. Cyberpsychol Behav Soc Netw 14: 591-596.

11. Rehbein F, Kleimann M, Mößle T (2009) Computerspielabhängigkeit im Kindesund Jugendalter. (KFN-Forschungsberichte, Nr. 108), Kriminologisches Forschungsinstitut Niedersachsen, Hannover.

12. American Psychiatric Association (2013) Diagnostic and Statistical Manual of Mental Disorders. (5thedn), American Psychiatric Association, Washington DC.

13. Young KS (1998) Caught in the net: How to recognize the signs of Internet addiction - And a winning strategy for recovery. Wiley, Hoboken.

14. Meerkerk GJ, Van Den Eijnden RJ, Vermulst AA, Garretsen HF (2009) The Compulsive Internet Use Scale (CIUS): some psychometric properties. Cyberpsychol Behav 12: 1-6.
15. Caplan SE (2010) Theory and measurement of generalized problematic Internet use: A two-step approach. Computers in Human Behavior 26: 10891097.

16. American Psychiatric Association (2000) Diagnostic and Statistical Manual of Mental Disorders. (4th edn) Text Revision. American Psychiatric Association, Washington, DC

17. Griffiths M (1999) Internet addiction: fact or fiction? Psychologist 12: 246-250.

18. Widyanto L, McMurran M (2004) The psychometric properties of the internet addiction test. Cyberpsychol Behav 7: 443-450.

19. Widyanto L, Griffiths MD, Brunsden V (2011) A psychometric comparison of the Internet Addiction Test, the Internet-Related Problem Scale, and self-diagnosis. Cyberpsychol Behav Soc Netw 14: 141-149.

20. Chang MK, Man Law SP (2008) Factor structure for Young's Internet Addiction Test: A confirmatory study. Computers in Human Behavior 24: 2597-2619.

21. Khazaal Y, Billieux J, Thorens G, Khan R, Louati Y, et al. (2008) French validation of the internet addiction test. Cyberpsychol Behav 11: 703-706.

22. Barke A, Nyenhuis N, Kröner-Herwig B (2012) The German version of the internet addiction test: a validation study. Cyberpsychol Behav Soc Netw 15 534-542.

23. Edwards P, Roberts I, Sandercock P, Frost C (2004) Follow-up by mail in clinical trials: does questionnaire length matter? Control Clin Trials 25: 31-52.

24. Horn Jl (1965) A rationale and test for the number of factors In factor analysis psychometrika 30: 179-185.

25. Schreiber JB, Nora A, Stage FK, Barlow, EA King, J (2006) Reporting Structural Equation Modeling and Confirmatory Factor Analysis Results: A Review. The Journal of Educational Research 99: 323-337.

26. Yee $\mathrm{N}$ (2006) The demographics, motivations and derived experiences of users of massively-multiuser online graphical environments. Presence: Teleoperators and Virtual Environments 15: 309-329.

27. Griffiths MD, Davies MN, Chappell D (2003) Breaking the stereotype: the case of online gaming. Cyberpsychol Behav 6: 81-91.

28. Griffiths MD, Davies MN, Chappell D (2004) Demographic factors and playing variables in online computer gaming. Cyberpsychol Behav 7: 479-487.

29. Kim EJ, Namkoong K, Ku T, Kim SJ (2008) The relationship between online game addiction and aggression, self-control and narcissistic personality traits. Eur Psychiatry 23: 212-218.

30. Desai RA, Krishnan-Sarin S, Cavallo D, Potenza MN (2010) Video-gaming among high school students: health correlates, gender differences, and problematic gaming. Pediatrics 126: e1414-1424.

31. Griffiths MD, Davies MN, Chappell D (2004) Online computer gaming: a comparison of adolescent and adult gamers. J Adolesc 27: 87-96.

32. Achab S, Nicolier M, Mauny F, Monnin J, Trojak B, et al. (2011) Massively multiplayer online role-playing games: comparing characteristics of addict vs non-addict online recruited gamers in a French adult population. BMC Psychiatry 11: 144. Uga. Itaecatia voluptaecus duciment.

Submit your next manuscript and get advantages of OMICS Group submissions

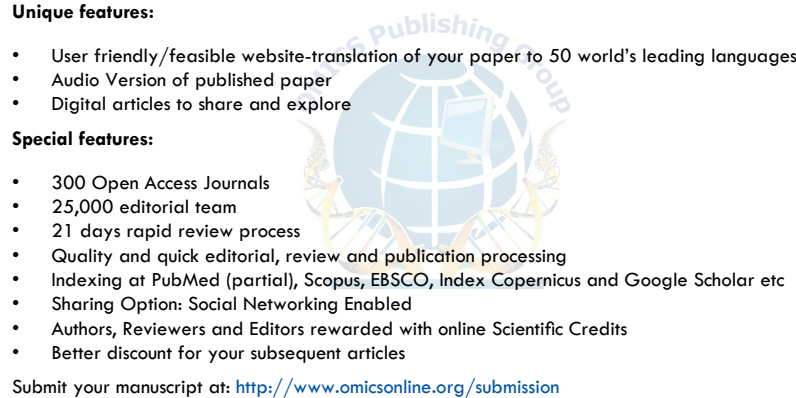

